\title{
Near-Infrared Spectroscopy of the Bladder: New Parameters for Evaluating Voiding Dysfunction
}

\author{
Andrew Macnab, ${ }^{1,2}$ Babak Shadgan, ${ }^{1}$ Kourosh Afshar, ${ }^{3}$ and Lynn Stothers ${ }^{1}$ \\ ${ }^{1}$ Departments of Paediatrics and Urology, UBC Hospital Bladder Care Centre, Faculty of Medicine, University of British Columbia, \\ Unit 1B Room F329, 221 Wesbrook Mall, Vancouver, BC, Canada V6T $1 Z 3$ \\ ${ }^{2}$ Stellenbosch Institute for Advanced Study, Wallenberg Research Centre, 10 Marais Street, Stellenbosch 7600, South Africa \\ ${ }^{3}$ Department of Urology, British Columbia's Children's Hospital, Faculty of Medicine, Room K0-134, 4480 Oak Street, \\ Vancouver, BC, Canada V6H 3 V4
}

Correspondence should be addressed to Andrew Macnab, amacnab@cw.bc.ca

Received 25 December 2010; Accepted 13 March 2011

Academic Editor: Maher S. Amer

Copyright (C) 2011 Andrew Macnab et al. This is an open access article distributed under the Creative Commons Attribution License, which permits unrestricted use, distribution, and reproduction in any medium, provided the original work is properly cited.

\begin{abstract}
We describe innovative methodology for monitoring alterations in bladder oxygenation and haemodynamics in humans using near-infrared spectroscopy (NIRS). Concentrations of the chromophores oxygenated $\left(\mathrm{O}_{2} \mathrm{Hb}\right)$ and deoxygenated ( $\left.\mathrm{HHb}\right)$ haemoglobin and their sum (total haemoglobin) differ during bladder contraction in health and disease. A wireless device that incorporates three paired light emitting diodes (wavelengths 760 and 850 nanometers) and silicon photodiode detector collects data transcutaneously $(10 \mathrm{~Hz})$ with the emitter/detector over the bladder during spontaneous bladder emptying. Data analysis indicates comparable patterns of change in chromophore concentration in healthy children and adults (positive trend during voiding, predominantly due to elevated $\mathrm{O}_{2} \mathrm{Hb}$ ), but different changes in symptomatic subjects with characteristic chromophore patterns identified for voiding dysfunction due to specific pathophysiologies: bladder outlet obstruction (males), overactive bladder (females), and nonneurogenic dysfunction (children). Comparison with NIRS muscle data suggests altered bladder haemodynamics and/or oxygenation may underlie voiding dysfunction offering new insight into the causal physiology.
\end{abstract}

\section{Introduction}

Near-infrared spectroscopy (NIRS) is an established noninvasive optical technique, which uses light in the nearinfrared (NIR) spectrum $(700-1000 \mathrm{~nm})$ to monitor tissue oxygenation and haemodynamics transcutaneously by measuring changes in chromophore concentration in the microcirculation (oxygenated $\left[\mathrm{O}_{2} \mathrm{Hb}\right]$ and deoxygenated [HHb] haemoglobin) [1-4]. These changes (expressed as $\mu \mathrm{mol} / 100 \mathrm{~mL}$ ) are measured in real-time as a change relative to baseline. Changes in total haemoglobin concentration $[\mathrm{tHb}]$ (the sum of $\left[\mathrm{O}_{2} \mathrm{Hb}\right]$ and $[\mathrm{HHb}]$ ) indicate change in blood volume $[5,6]$. The physics principles underlying this technology, the wide range of research using NIRS $[1,3,4]$, and the NIRS-derived parameters with validated methods of measurement [3] have been comprehensively described. However, urological applications are recent, and NIRS monitoring of the bladder (detrusor muscle) is a novel use of NIRS, and a disruptive technology in the context of the evaluation of voiding dysfunction, as a noninvasive measure of changes in oxygenation and haemodynamics during voiding is now feasible. The evolution and technical aspects of NIRS use in urology have been reviewed [4, 7]; evidence is accumulating that the patterns of change in $\left[\mathrm{O}_{2} \mathrm{Hb}\right],[\mathrm{HHb}]$, and $[\mathrm{tHb}]$ observed in the bladder microcirculation during the voiding cycle differ in health and disease, and algorithms based on noninvasive NIRS data have comparable discriminant ability to invasive pressure flow studies (the current clinical "gold standard") for diagnosing and classifying males with lower urinary tract symptoms as either obstructed or unobstructed [8-10].

Confidence that NIRS monitoring of the bladder contributes novel physiologic information comes from: existing knowledge of the physics of NIR light penetration, scattering, and absorption in tissue $[1,3]$; research studies, predominantly on muscle, showing that vascular pathology 
involving the microcirculation affects tissue haemodynamics and oxygenation [1, 2, 5]; and understanding of the physiologic mechanisms that determine how a functional microcirculation provides for and responds to changes in oxygen demand [11-13]. Prior urologic research has identified that functional and structural abnormalities in the bladder are associated with decreased blood flow in the organ's microcirculation. During normal cyclic filling and emptying blood vessels must lengthen and shorten while maintaining adequate muscle perfusion [14] and blood flow depends largely on local regulation [15]. Various conditions decrease bladder blood flow including bladder outlet obstruction due to prostatic enlargement [16, 17]. Changes in microvascular resistance may be secondary to structural changes in the bladder wall and vasculature [18]. Decreased blood flow and reduced bladder wall compliance are correlated; ischemia impairs compliance and contractility and may lead to structural change $[15,18]$.

NIRS studies on the surgically exposed rabbit bladder show identical effects in response to hypoxia to those seen using NIRS in other tissues [19]. In the human, NIRS-derived voiding changes are only detected with an emitter/detector over the bladder (not elsewhere on the abdomen); and dynamic changes in $\left[\mathrm{O}_{2} \mathrm{Hb}\right],[\mathrm{HHb}]$, and [tHb] occur in the detrusor during sustained urge without passage of urine (when bladder volume and position are constant) which indicates NIRS detects physiologic change rather than volume- or movement-mediated effects [20].

The initial urological research used NIRS instruments with lasers $[4,7-10,19,21,22]$; however, the size and configuration of such instruments constrains patients. A miniature wireless device with light emitting diodes (LEDs) in place of lasers developed for muscle studies [23] has been used in a pilot study $[20,24]$ to confirm the feasibility of wireless bladder monitoring in ambulant subjects. Conventional and wireless instruments (interfaces illustrated in Figure 1) identify that NIRS patterns of change in chromophore concentration differ between asymptomatic subjects and those with voiding dysfunction and that characteristic patters occur with specific bladder pathologies [7-10, 20, 24].

This report describes a study to further explore the use of wireless NIRS in asymptomatic and symptomatic subjects, and analyze the chromophore changes obtained during spontaneous voiding using physiologic interpretation from NIRS muscle studies. Our hypothesis was that a consistent pattern of change in chromophore concentration $\left[\mathrm{O}_{2} \mathrm{Hb}\right]$, $[\mathrm{HHb}]$, and $[\mathrm{tHb}]$ occurs in asymptomatic subjects that reflects a balance in oxygen supply and demand in response to bladder contraction and that this pattern would differ in children with voiding dysfunction and suggest impairment of detrusor haemodynamics and/or oxygenation, if the changes observed paralleled NIRS muscle data where changes in oxygen supply and demand occur due to local or systemic pathology or were induced experimentally.

\section{Methods}

This study received ethical approval (H08-01443) from the University of British Columbia.

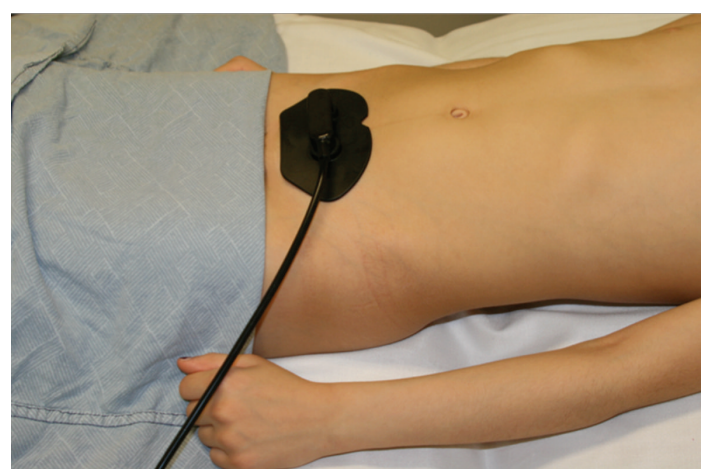

(a)

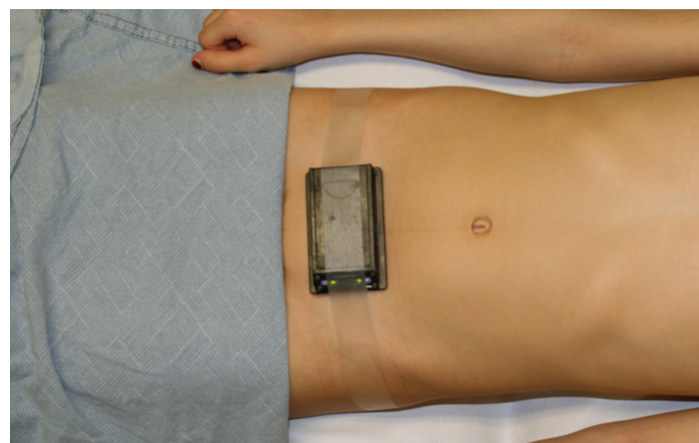

(b)

Figure 1: A laser-powered instrument's fiber optic cable and emitter detector interface attached over the bladder of a child; and a selfcontained led-powered device positioned for bladder monitoring.

2.1. Participants. A cohort of children referred for evaluation of symptoms of lower urinary tract dysfunction and diagnosed with nonneurogenic lower urinary tract dysfunction (NLUTD) and a convenience sample of healthy asymptomatic adults and children.

2.2. Instrumentation. The full specifications of the instrument ("PortaMon", Artinis Medical Technologies, BV, the Netherlands) have been described [23]. Features making the device ideal for urologic study include: compact dimensions, weight $84 \mathrm{gm}$, size $83 \times 52 \times 20 \mathrm{~cm}$; LEDs with wavelengths of 760 and $850 \mathrm{~nm}$, an incorporated emitter/detector interface with ambient light protection for transcutaneous transmission and detection of the optical signals, rechargeable battery, $10 \mathrm{~Hz}$ sampling, 2 megabyte internal memory; Bluetooth, real-time data transfer to a remote computer for graphic display, and software algorithms based on existing instrumentation [22]. Data was collected using a $4 \mathrm{~cm}$ emitter/detector distance in adults and $3.5 \mathrm{~cm}$ in children.

2.3. Procedure. Following informed consent, the NIRS device was attached to the skin of the anterior abdominal wall using double-sided adhesive discs (3M, Saint Paul, Minn, USA), with the emitter/detector interface across the midline $2 \mathrm{~cm}$ superior to the symphysis pubis (the site used previously for bladder NIRS) [7, 8, 21]. Subjects could then remain 
TABLE 1: Children diagnosed with non neurogenic lower urinary tract dysfunction*.

\begin{tabular}{|c|c|c|c|c|c|c|c|c|}
\hline & Age (yrs) & Gender & Weight (Kg) & BMI & Symptoms & PVR & $\begin{array}{l}\text { Voided volume } \\
\qquad(\mathrm{mL})\end{array}$ & $\begin{array}{l}\text { Average flow } \\
(\mathrm{mL} / \mathrm{s})\end{array}$ \\
\hline (1) & 3 & Female & 14 & 16.3 & Recurrent UTI, enuresis & 20 & 140 & 5.3 \\
\hline (2) & 10 & Female & 35 & 17.2 & Frequency, urgency & 0 & 91 & 10.1 \\
\hline (3) & 9 & Female & 31 & 17.4 & $\begin{array}{l}\text { Recurrent UTI, } \\
\text { frequency }\end{array}$ & 122 & 134 & 8.9 \\
\hline (4) & 14 & Male & 42 & 18.7 & $\begin{array}{l}\text { infrequent voiding, } \\
\text { dysuria }\end{array}$ & 150 & 466 & 7.2 \\
\hline (5) & 7 & Male & 28 & 15.9 & $\begin{array}{l}\text { infrequent voiding, } \\
\text { incontinence }\end{array}$ & 175 & 298 & 5.7 \\
\hline (6) & 5 & Female & 24 & 16.6 & Frequency, incontinence & 19 & 190 & 8.2 \\
\hline (7) & 12 & Male & 46 & 23.8 & frequency & 36 & 102 & 6.6 \\
\hline (8) & 11 & female & 42 & 29.1 & Frequency, urgency & 13 & 283 & 15.4 \\
\hline (9) & 7 & female & 25 & 18.9 & Recurrent UTI & 0 & 140 & 8.8 \\
\hline (10) & 8 & female & 25 & 24.2 & incontinence, enuresis & 18 & 108 & 5.2 \\
\hline (11) & 7 & female & 22 & 16.6 & frequency & 0 & 50 & 5.3 \\
\hline (12) & 6 & Male & 23 & 16 & frequency & 68 & 140 & 12.1 \\
\hline (13) & 14 & Male & 60 & 26.2 & $\begin{array}{l}\text { Dysuria, infrequent } \\
\text { voiding }\end{array}$ & 36 & 322 & 10.7 \\
\hline (14) & 4 & male & 16 & 29 & incontinence, enuresis & 0 & 57 & 6.7 \\
\hline (15) & 7 & Male & 26 & 17.2 & Frequency, urgency & 21 & 319 & 11.6 \\
\hline (16) & 11 & female & 15 & 18 & Urgency, hematuria & 22 & 96 & 6.2 \\
\hline
\end{tabular}

Key UTI: urinary tract infection.

${ }^{*}$ Diagnostic criteria for NLUTD reference [25].

ambulant and were provided with water to drink to naturally fill the bladder.

Prior to voiding subjects were asked to stand (adults) or sit (children) and remain still, baseline data was obtained, then permission to void (naturally and without abdominal straining) was given, with monitoring continuing at $10 \mathrm{~Hz}$ beyond the end of urine flow. The device was removed, and graphic display of chromophore concentration from each study generated. Times for permission to void, the start and end of urine flow were obtained, and in symptomatic subjects a conventional uroflow scale (Laborie Medical Technologies Inc., Mississauga, ON, Canada) was used to measure voided volume, peak and average flow.

2.4. Data Analysis. The difference between the NIR light emitted into the tissue and the photons returning was used to derive changes in $\left[\mathrm{O}_{2} \mathrm{Hb}\right]$ and $[\mathrm{HHb}]$, and $[\mathrm{tHb}]$ from raw optical data using proprietary software [22]. Graphs of chromophore change against time for each void in each subject were analyzed to identify overall consistency in the patterns of change and define whether an increase, and decrease or plateau was evident in $\left[\mathrm{O}_{2} \mathrm{Hb}\right],[\mathrm{HHb}]$, and $[\mathrm{tHb}]$ at or during 3 phases of voiding: on permission to void, following the start of urine flow and over the duration of voiding (bladder contraction). Visual comparison was then made within and between 3 sets of graphs: (1) all asymptomatic adults, (2) all asymptomatic children, and (3) all children with symptoms of lower urinary tract dysfunction. Comparison was made visually rather than mathematically because the duration of voiding, volume voided, and magnitude of chromophore change would show individual variation.

\section{Results}

37 subjects were enrolled: 16 asymptomatic adults (19-41 years), 5 asymptomatic children (5-17 years), and 16 symptomatic children (with NLUTD Table 1). The wireless device monitored data successfully in each subject.

In all asymptomatic subjects the pattern of change in chromophore concentration from permission to void to uroflow end was comparable, although the magnitude of change and duration of voiding varied between individuals. Figures 2 and 3 illustrate 4 graphs of representative patterns for asymptomatic adults and children, respectively. All asymptomatic subjects showed 3 consistent elements during the 3 phases of voiding analyzed: (1) a brief initial increase in $\left[\mathrm{O}_{2} \mathrm{Hb}\right]$ and $[\mathrm{tHb}]$ on permission to void, (2) a greater and longer sustained increase following the start of uroflow, and (3) a strong positive trend in $\left[\mathrm{O}_{2} \mathrm{Hb}\right]$, with minimal or no change in $[\mathrm{HHb}]$, throughout or for the majority of the voiding cycle.

In symptomatic children with NLUTD the patterns of change were markedly different although there were obvious intersubject similarities. Four examples of the commonest pattern are shown in Figure 4. All symptomatic children showed a predominantly negative trend in $\left[\mathrm{O}_{2} \mathrm{Hb}\right]$ and $[\mathrm{tHb}]$ in contrast to the positive trend seen in asymptomatic children. During the 3 phases of voiding: little or no increase 


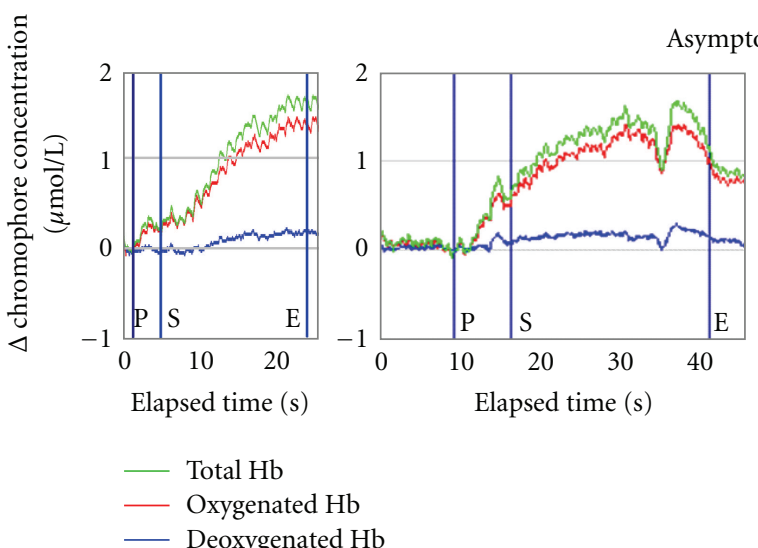

(a) (b)

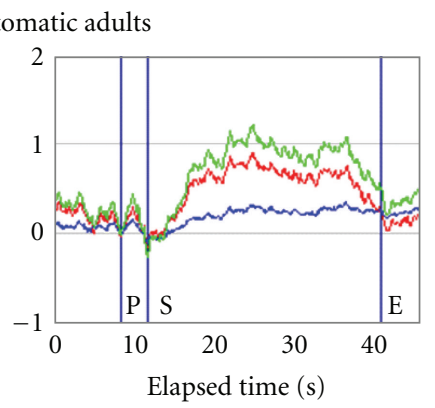

P: permission to void

S: urine flow starts

E: urine flow ends

(c)

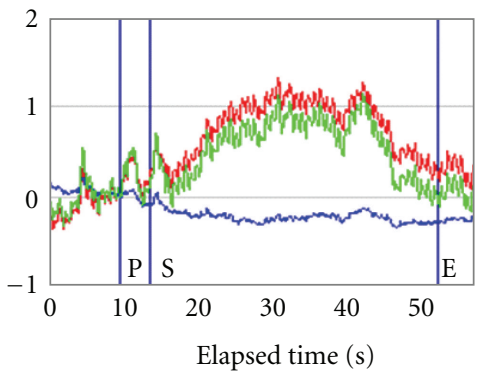

Elapsed time (s)

(d)

FIGURE 2: Chromophore voiding patterns in asymptomatic adults. Examples of the patterns of change in detrusor chromophore concentration $\left[\mathrm{O}_{2} \mathrm{Hb}\right],[\mathrm{HHb}]$, and [tHb] from 4 asymptomatic adults ( (a) $19 \mathrm{yrs}$, (b) $22 \mathrm{yrs}$, (c) $\left.32 \mathrm{yrs},(\mathrm{d}) 41 \mathrm{yrs}\right)$. [O $\left.\mathrm{O}_{2} \mathrm{Hb}\right]$ is increased for the majority of the voiding cycle, with an associated rise in $[\mathrm{tHb}]$, while change in $[\mathrm{HHb}]$ is minimal. The overall trend of $\left[\mathrm{O}_{2} \mathrm{Hb}\right]$ and $[\mathrm{tHb}]$ is positive for all or the majority of the voiding cycle. These patterns are also comparable to those from asymptomatic children (Figure 3).

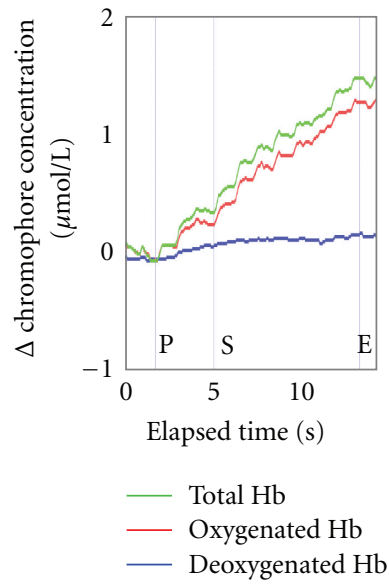

(a)

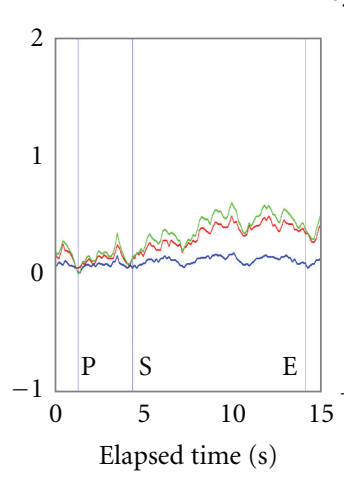

(b)
Asymptomatic children
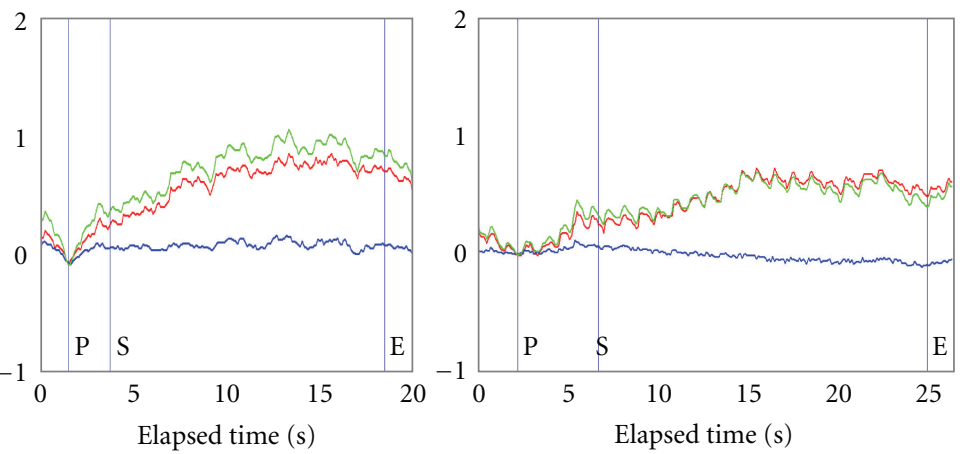

P: permission to void

S: urine flow starts

E: urine flow ends

(c) (d)

FIGURE 3: Chromophore voiding patterns in asymptomatic children. Examples of NIRS data sets from 4 asymptomatic children ((a) 12 yrs, (b) $5 \mathrm{yrs}$, (c) $13 \mathrm{yrs}$, (d) $15 \mathrm{yrs}$ ). A positive trend in $\left[\mathrm{O}_{2} \mathrm{Hb}\right]$ and $[\mathrm{tHb}]$ is evident which begins on permission to void and continues for all or the majority of uroflow, while $[\mathrm{HHb}]$ remains essentially unaltered.

in $\left[\mathrm{O}_{2} \mathrm{Hb}\right]$ occurred on permission to void, with the majority of children having a downward trend. Following the start of urine flow $\left[\mathrm{O}_{2} \mathrm{Hb}\right]$ and $[\mathrm{tHb}]$ usually fell further (some showed a delayed, temporary, or intermittent rise during urination); and a negative trend in $\left[\mathrm{O}_{2} \mathrm{Hb}\right]$, sometimes with periods of major decrease, with lesser change in $[\mathrm{HHb}]$ was evident for a large part of voiding.

In 3 children $\left[\mathrm{O}_{2} \mathrm{Hb}\right]$ declined steeply on permission to void with an opposite and almost equal increase in [HHb], while $[\mathrm{tHb}]$ remained essentially unchanged, this overall chromophore trend continued throughout voiding. These children had severe symptoms; Figure 5 is a representative example of this pattern with the relationship to uroflow and voided volume illustrated.

\section{Discussion}

This study reports wireless NIRS monitoring of changes in chromophore concentration in the detrusor microcirculation during voiding. The wireless system was particularly useful in studies involving children; its small size and ease of application generated no anxiety, limitation 


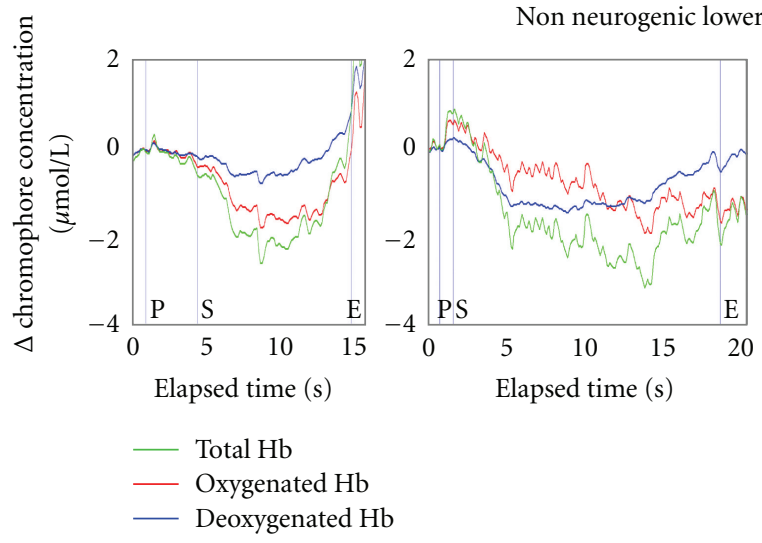

(a) (b)

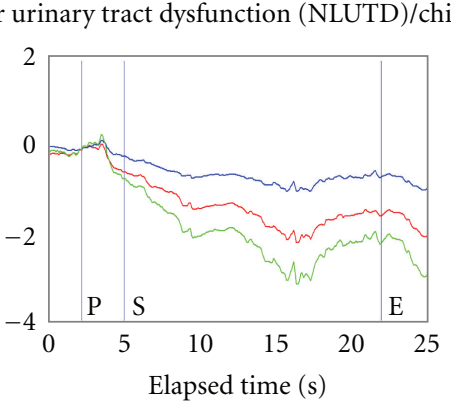

P: permission to void

S: urine flow starts

E: urine flow ends

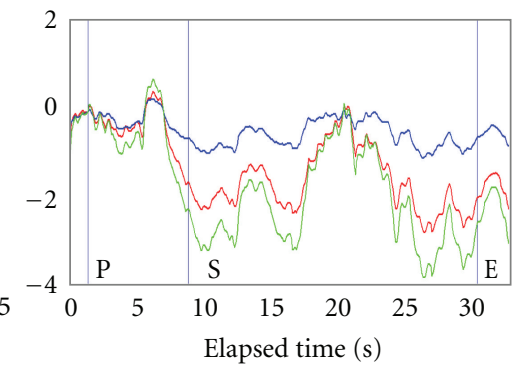

Elapsed time (s)

(c)

(d)

FIGURE 4: Chromphore voiding patterns in children with dysfunctional voiding. Examples of NIRS data sets from 4 symptomatic children with NLUTD, all show a negative trend in $\left[\mathrm{O}_{2} \mathrm{Hb}\right]$ and $[\mathrm{tHb}]$ from permission to void that continues through uroflow start. Marked decreases in $\left[\mathrm{O}_{2} \mathrm{Hb}\right]$ and $[\mathrm{tHb}]$ occur in all subjects, some have periods of intermittent unsustained rise or an increase towards uroflow end, but all show a fall in $\left[\mathrm{O}_{2} \mathrm{Hb}\right]$ and $[\mathrm{tHb}]$ during a substantial portion of the voiding cycle, while $[\mathrm{HHb}]$ shows lesser degrees of change.

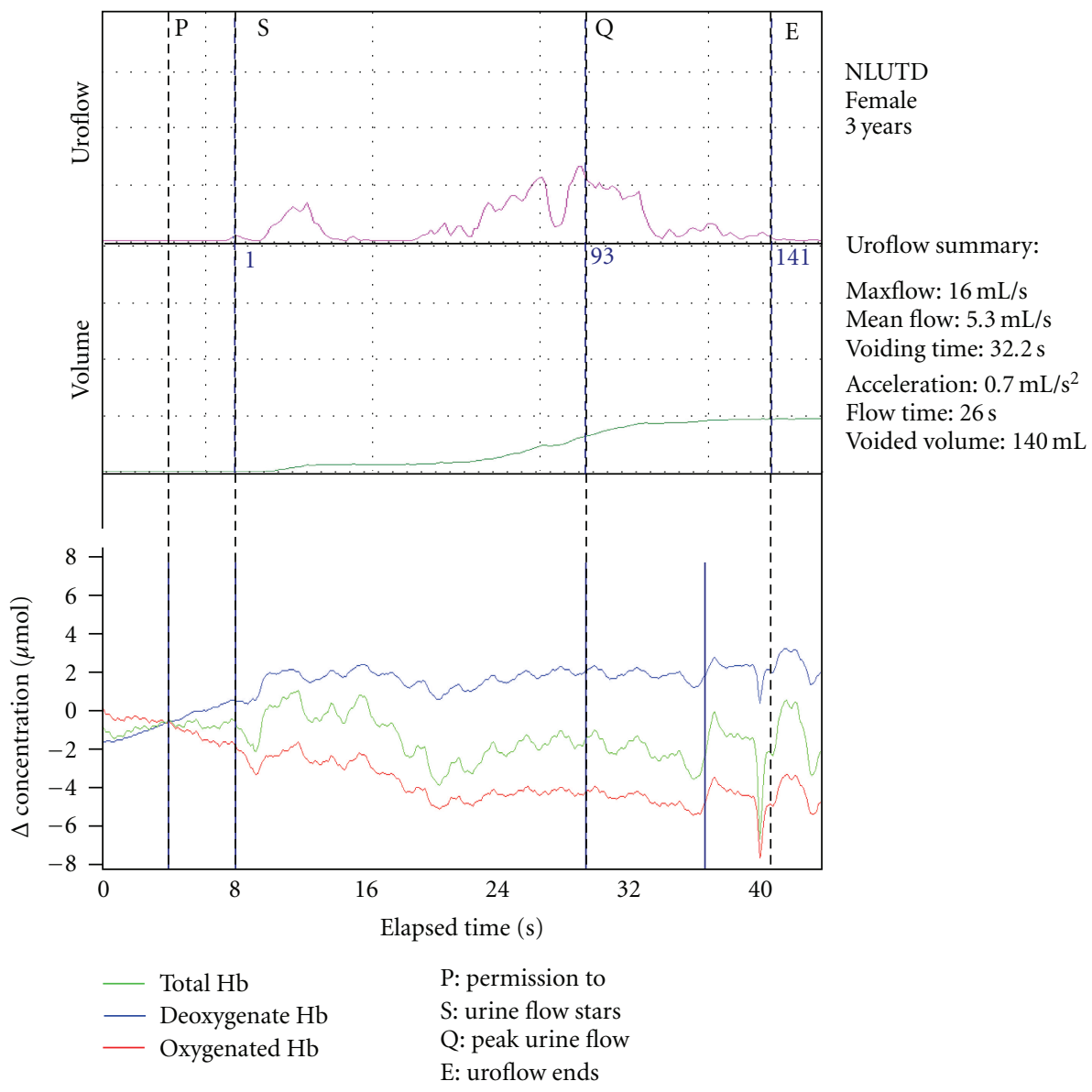

FIGURE 5: Simultaneous data (uroflow, voided volume, and NIRS pattern of chromophore change) in a child with severe symptoms of nonneurogenic lower urinary tract dysfunction. Following permission to void a sharp decrease in $\left[\mathrm{O}_{2} \mathrm{Hb}\right]$ is evident with a coincident equal and opposite increase in [HHb] (5-10 seconds), while [tHb] remains stable (see similarity in Figure 6, 785-790 seconds). Between uroflow start and uroflow end $\left[\mathrm{O}_{2} \mathrm{Hb}\right]$ shows an overall downward trend while [HHb] rises further initially and then plateaus. [tHb] rises briefly and then falls reflecting simultaneous changes in $\left[\mathrm{O}_{2} \mathrm{Hb}\right]$ and $[\mathrm{HHb}]$. The overall chromophore pattern during voiding implies an imbalance of oxygen supply and demand and the potential for muscle fatigue due to oxygen debt. 
of spontaneous movement, or compromise in ability to void. NIRS monitoring of the bladder is an innovative application of spectroscopy to a clinical area that currently relies on invasive studies for diagnosis that are limited to measurement of pressure and flow. While the first urologic studies appropriately looked to compare noninvasive NIRS data with pressure flow data, researchers and clinicians now need to consider the novel information that trends and patterns of change in NIRS parameters can provide in their own right when interpreted in the context of similar data in other tissues generated by physiologic change.

A consistent pattern of change in $\left[\mathrm{O}_{2} \mathrm{Hb}\right],[\mathrm{HHb}]$, and $[\mathrm{tHb}]$ was observed in asymptomatic children and adults; a difference was seen between this asymptomatic "normal" pattern and the chromophore change monitored in children with dysfunctional voiding. NIRS monitors changes in $\left[\mathrm{O}_{2} \mathrm{Hb}\right]$ and $[\mathrm{HHb}]$ in all compartments of the microcirculation (arterial, capillary, and venous) [1, $4,5]$, and thus reflects the dynamic relationship between haemodynamic changes in the microcirculation and tissue oxygen delivery and utilization [2]. Interpreted in the context of the physiologic changes and effects on muscle function described in NIRS studies of skeletal muscle $[1-3,5,6$, 26-28], the chromophore patterns we observed support our hypothesis that changes in detrusor $\left[\mathrm{O}_{2} \mathrm{Hb}\right],[\mathrm{HHb}]$, and $[\mathrm{tHb}]$ reflect whether or not the hemodynamic and oxygenation requirements of the bladder are being met during contraction.

In health the microvasculature maintains tissue oxygenation in response to variations in metabolic demand [1113] via "an ensemble of (neuronal-, endothelial-, and erythrocyte-mediated) signaling pathways" [13]. These integrate smooth muscle and endothelial cell function, determine convection and diffusion of oxygen, and dictate where blood flow is distributed [11]. Initially when muscle contracts terminal arteriole calibre increases, then as metabolic demand rises intermediate and proximal arterioles are recruited $[12,13]$. Thus the normal hemodynamic response to the onset of contraction is an increase in blood volume [tHb] $[5,6,26]$, with the proportional contribution of an increase in $\left[\mathrm{O}_{2} \mathrm{Hb}\right]$ or $[\mathrm{HHb}]$ depending on the level of workload $[6,26]$. In light exercise, arterial inflow may exceed oxygen utilization [5] that is, $\left[\mathrm{O}_{2} \mathrm{Hb}\right]$ and $[\mathrm{tHb}]$ will increase, as we observed in asymptomatic subjects at the start of voiding.

However, microvascular function is influenced by the health of the subject, the "fitness" of the muscle, and the workload required for contraction $[2,5,12,26]$. Where systemic or regional pathology affecting the microcirculation impairs oxidative metabolism organ function is compromised and symptoms occur $[2,11,13]$; exercise intolerance and fatigue in voluntary muscle reflect the negative impact of myocardial dysfunction, peripheral vascular disease, and ischemia on the microcirculation $[2,5,26,29]$, and an intraorgan deficit of blood flow related to abnormal vascular reactivity is described [13].

Figure 6 shows raw data from a NIRS muscle experiment [6] where rhythmic isometric handgrip exercise was followed by arterial occlusion. The patterns of change and

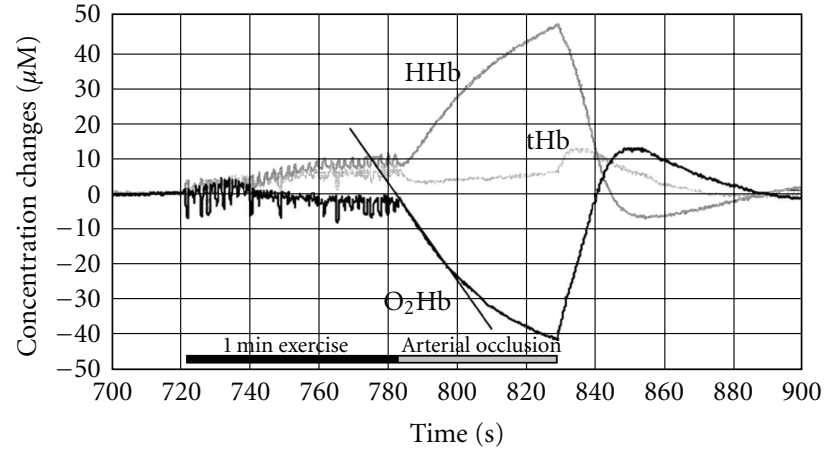

FIGURE 6: A NIRS study of the effects of forearm muscle contraction and induced ischemia on chromophore change. Reproduced with permission from; [6]. Raw NIRS signals during 1 min of rhythmic isometric handgrip exercise at $20 \%$ of the maximum voluntary contraction force (MVC) followed by 45 seconds of arterial occlusion (sphygmomanometer generated). The sum of $\left[\mathrm{O}_{2} \mathrm{Hb}\right]$ and $[\mathrm{HHb}]$ reflects the total amount of haemoglobin $[\mathrm{tHb}]$ (interpreted as change in blood volume in tissue). When exercise begins an increase in $\left[\mathrm{O}_{2} \mathrm{Hb}\right]$ is evident that overlies the coincident change in $[\mathrm{tHb}](720-740 \mathrm{sec})$. This reflects a normal hemodynamic response. With continued isometric contraction (740-780 sec) a progressive increase in $[\mathrm{HHb}]$ and rise in $[\mathrm{tHb}]$ with coincident decline in $\left[\mathrm{O}_{2} \mathrm{Hb}\right]$ occurs. This reflects increasing oxygen extraction and higher blood volume. Following arterial occlusion (and tissue hypoxia), an abrupt increase in [HHb] is matched by an equal and opposite decrease in $\left[\mathrm{O}_{2} \mathrm{Hb}\right]$ and $[\mathrm{tHb}]$ plateaus. This reflects the cumulative effects of tissue hypoxia, oxygen debt, and stable blood volume. On release of occlusion $(830 \mathrm{sec}),\left[\mathrm{O}_{2} \mathrm{Hb}\right]$ rebounds above baseline with an associated increase in $[\mathrm{tHb}]$ and fall in $[\mathrm{HHb}]$. This reflects reperfusion with increased oxygenated blood volume and recovery of tissue oxygenation. A return of $\left[\mathrm{O}_{2} \mathrm{Hb}\right]$, $[\mathrm{HHb}]$, and $[\mathrm{tHb}]$ to baseline $(890 \mathrm{sec})$ indicates recovery of normal haemodynamics and oxygenation.

proportional contributions of $\left[\mathrm{O}_{2} \mathrm{Hb}\right]$ and $[\mathrm{HHb}]$ to $[\mathrm{tHb}]$ demonstrate hemodynamic change occurring with the onset of contraction, increased oxygen extraction in response to one minute of continued contraction, and the effects of tissue hypoxia and oxygen debt during arterial occlusion.

During normal voiding (asymptomatic subjects) our data indicates that an increase in $\left[\mathrm{O}_{2} \mathrm{Hb}\right]$ occurs with a resultant rise in blood volume $[\mathrm{tHb}]$ in the detrusor, while $[\mathrm{HHb}]$ changes are small. In the context of the microcirculation [11-13], this reflects a response that provides fully for the metabolic requirements of normal muscle function through an increase in $\left[\mathrm{O}_{2} \mathrm{Hb}\right]$ that exceeds oxygen demand $[5,26]$. Conversely, in children with NLUTD there is no increase in $\left[\mathrm{O}_{2} \mathrm{Hb}\right]$, and during bladder contraction (urine flow) $\left[\mathrm{O}_{2} \mathrm{Hb}\right]$ and $[\mathrm{tHb}]$ decrease. Physiologically, this implies blunting or a lack of the haemodynamic response required to provide energy for detrusor contraction, and the potential for fatigue (exercise intolerance), as happens in striated muscle when oxygen demand exceeds supply $[5,29,30]$. In 3 children with NLUTD a more extreme voiding chromophore pattern occurred (Figure 5). Here, the abrupt decrease in $\left[\mathrm{O}_{2} \mathrm{Hb}\right]$ and coincident increase in $[\mathrm{HHb}]$ following permission to void (5-10 seconds) match the 
characteristic NIRS patterns observed in muscle [4-6, 26] and the rabbit bladder [19] in response to hypoxia, and are the same in terms of directional trends to those evident when oxygen debt develops following the onset of arterial occlusion in Figure 6 (785-790 seconds). As children with NLUTD have no known anatomical or neurological basis for their symptoms [31], it is possible that the physiological basis for their voiding dysfunction could reflect disordered detrusor haemodynamics and oxygenation.

Our findings are also consistent with the known association of reduced bladder blood flow with decreased bladder wall compliance, interstitial cystitis, bladder outlet obstruction (BOO) and aging [14-17], and our prior findings of impaired oxygenation in patients symptomatic with $\mathrm{BOO}$ [9] and in pilot data from a subset of women with detrusor over activity. Hence, the probability that NIRS changes in chromophore concentration reflect the dynamic and sometimes multidirectional relationship that exists between tissue oxygen delivery and consumption and haemodynamic changes in the microcirculation of the detrusor during voiding, and the rationale for voiding chromophore patterns being different in health and disease.

Limitations. This study used new wireless technology; applications of NIRS involving the bladder are recent; the number of subjects studied is small; variations in the magnitude of change are evident between data sets; the protocol did not include monitoring during natural filling; the bladder was not filled to a standardized volume, and monitoring did not address potential differences in regional blood flow.

However, other NIRS studies [2, 4-6] show that variations in chromophore magnitude occur due to differences in light penetration and scattering, and indicate that the chromophore patterns we obtained have a measure of reproducibility and that small variations in chromophore concentration which might be considered relevant changes are within the limits of measurement. Further research is required to corroborate our observations and requires parallel standard urologic evaluation. However, we believe our findings are relevant and add to the rationale for confidence that NIRS monitors physiologic changes in the detrusor microcirculation.

\section{Conclusion}

NIRS can monitor changes in $\left[\mathrm{O}_{2} \mathrm{Hb}\right],[\mathrm{HHb}]$, and blood volume $[\mathrm{tHb}]$ reflecting hemodynamic and oxygenationrelated changes in the bladder during voiding. NIRS adds new noninvasive parameters for evaluation of voiding dysfunction; these differ in health and disease; wireless technology expands the potential of NIRS use, particularly in children and could expand urologic evaluation and research. Voiding chromophore patterns have consistent features in asymptomatic subjects including a positive trend with increasing $\left[\mathrm{O}_{2} \mathrm{Hb}\right]$ and $[\mathrm{tHb}]$ in the detrusor microcirculation. In children with dysfunctional voiding such patterns were consistently different with a negative trend and fall in $\left[\mathrm{O}_{2} \mathrm{Hb}\right]$ and $[\mathrm{tHb}]$. These differences suggest impairment of detrusor haemodynamics and/or oxygenation may underlie these children's symptoms.

\section{References}

[1] M. Ferrari, L. Mottola, and V. Quaresima, "Principles, techniques, and limitations of near infrared spectroscopy," Canadian Journal of Applied Physiology, vol. 29, no. 4, pp. 463487, 2004.

[2] T. Hamaoka, K. K. McCully, V. Quaresima, K. Yamamoto, and B. Chance, "Near-infrared spectroscopy/imaging for monitoring muscle oxygenation and oxidative metabolism in healthy and diseased humans," Journal of Biomedical Optics, vol. 12, no. 6, Article ID 062105, 2007.

[3] M. Wolf, M. Ferrari, and V. Quaresima, "Progress of nearinfrared spectroscopy and topography for brain and muscle clinical applications," Journal of Biomedical Optics, vol. 12, no. 6, Article ID 062104, 2007.

[4] A. J. Macnab, "Biomedical applications of near infrared spectroscopy," in Biological and Biomedical Spectroscopy, A. Barth and P. Haris, Eds., vol. 2 of Advances in Biomedical Spectroscopy, pp. 305-402, IOS Press, Amsterdam, The Netherlands, 2009.

[5] R. Boushel, H. Langberg, J. Olesen, J. Gonzales-Alonzo, J. Bülow, and M. Kjær, "Monitoring tissue oxygen availability with near infrared spectroscopy (NIRS) in health and disease," Scandinavian Journal of Medicine and Science in Sports, vol. 11, no. 4, pp. 213-222, 2001.

[6] M. C. P. van Beekvelt, B. G. M. van Engelen, R. A. Wevers, and W. N. J. M. Colier, "In vivo quantitative near-infrared spectroscopy in skeletal muscle during incremental isometric handgrip exercise," Clinical Physiology and Functional Imaging, vol. 22, no. 3, pp. 210-217, 2002.

[7] L. Stothers, B. Shadgan, and A. Macnab, "Urological applications of near infrared spectroscopy," The Canadian Journal of Urology, vol. 15, no. 6, pp. 4399-4409, 2008.

[8] A. J. Macnab and L. Stothers, "Near-infrared spectroscopy: validation of bladder-outlet obstruction assessment using non-invasive parameters," The Canadian Journal of Urology, vol. 15, no. 5, pp. 4241-4248, 2008.

[9] L. Stothers, R. Guevara, and A. J. Macnab, "Classification of male lower urinary tract symptoms using mathematical modeling and a regression tree algorithm of non-invasive near infrared spectroscopy parameters," European Urology, vol. 57, no. 2, pp. 327-333, 2009.

[10] A. Te, D. E. Chung, R. I. Lee, and S. A. Kaplan, "Near infrared spectroscopy (NIRS) for application in urology," The Journal of Urology, vol. 181, no. 4, p. 601, 2009.

[11] R. N. Pittman, "Oxygen supply to contracting skeletal muscle at the microcirculatory level: diffusion vs. convection," Acta Physiologica Scandinavica, vol. 168, no. 4, pp. 593-602, 2000.

[12] C. G. Ellis, J. Jagger, and M. Sharpe, "The microcirculation as a functional system," Critical Care, vol. 9, no. 4, pp. S3-S8, 2005.

[13] S. S. Segal, "Regulation of blood flow in the microcirculation," Microcirculation, vol. 12, no. 1, pp. 33-45, 2005.

[14] A. F. Brading, J. E. Greenland, I. W. Mills, G. McMurray, and S. Symes, "Blood supply to the bladder during filling," Scandinavian Journal of Urology and Nephrology, Supplement, vol. 33, no. 201, pp. 25-31, 1999.

[15] R. T. Kershen, K. M. Azadzoi, and M. B. Siroky, "Blood flow, pressure and compliance in the male human bladder," The Journal of Urology, vol. 168, no. 1, pp. 121-125, 2002.

[16] A. T. L. Lin, M. T. Chen, C. H. Yang, and L. S. Chang, "Blood flow of the urinary bladder: effects of outlet obstruction and 
correlation with bioenergetic metabolism," Neurourology and Urodynamics, vol. 14, no. 3, pp. 285-292, 1995.

[17] A. Belenky, Y. Abarbanel, M. Cohen, O. Yossepowitch, P. M. Livne, and G. N. Bachar, "Detrusor resistive index evaluated by Doppler ultrasonography as a potential indicator of bladder outlet obstruction," Urology, vol. 62, no. 4, pp. 647-650, 2003.

[18] R. Kozlowski, M. B. Siroky, R. J. Krane, and K. M. Azadzoi, "Regulation of blood flow and microcirculation resistance in rabbit bladder," The Journal of Urology, vol. 168, no. 4, pp. 1608-1614, 2002.

[19] L. Stothers, A. J. Macnab, and B. Shadgan, "Detection of hypoxia within the detrusor using near infrared spectroscopy (NIRS)," The Journal of Urology, vol. 181, no. 4, p. 600, 2009.

[20] A. J. Macnab, L. Stothers, and B. Shadgan, "Wireless nearinfrared spectroscopy (NIRS) of the bladder detrusor during uroflow in ambulant children and adults," The Journal of Urology, vol. 181, no. 4, pp. 600-601, 2009.

[21] A. J. Macnab and L. Stothers, "Development of a near-infrared spectroscopy instrument for applications in urology," The Canadian Journal of Urology, vol. 15, no. 5, pp. 4233-4240, 2008.

[22] M. C. Van der Sluijs, W. N. J. M. Colier, R. J. F. Houston, and B. Oeseburg, "A new and highly sensitive continuous wave near infrared spectrophotometer with multiple detectors," in Proceedings of Photon Propagation in Tissues III, vol. 3194 of Proceedings of SPIE, San Remo, Italy, September 1997.

[23] B. Shadgan, W. D. Reid, R. Gharakhanlou, L. Stothers, and A. J. MacNab, "Wireless near-infrared spectroscopy of skeletal muscle oxygenation and hemodynamics during exercise and ischemia," Spectroscopy, vol. 23, no. 5-6, pp. 233-241, 2009.

[24] B. Shadgan, K. Afshar, L. Stothers, and A. Macnab, "Nearinfrared spectroscopy of the bladder: a new technique for studying lower urinary tract function in health and disease," in Photonic Therapeutics and Diagnostics VI, vol. 7548 of Proceedings of SPIE, San Francisco, Calif, USA, January 2010.

[25] K. Afshar, A. Mirbagheri, H. Scott, and A. E. MacNeily, "Development of a symptom score for dysfunctional elimination syndrome," The Journal of Urology, vol. 182, no. 4, supplement, pp. 1939-1943, 2009.

[26] M. Ferrari, T. Binzoni, and V. Quaresima, "Oxidative metabolism in muscle," Philosophical Transactions of the Royal Society B: Biological Sciences, vol. 352, no. 1354, pp. 677-683, 1997.

[27] Y. N. Bhambhani, "Muscle oxygenation trends during dynamic exercise measured by near infrared spectroscopy," Canadian Journal of Applied Physiology, vol. 29, no. 4, pp. 504523,2004

[28] V. Quaresima, R. Lepanto, and M. Ferrari, "The use of near infrared spectroscopy in sports medicine," Journal of Sports Medicine and Physical Fitness, vol. 43, no. 1, pp. 1-13, 2003.

[29] G. Murthy, A. R. Hargens, S. Lehman, and D. M. Rempel, "Ischemia causes muscle fatigue," Journal of Orthopaedic Research, vol. 19, no. 3, pp. 436-440, 2001.

[30] M. C. P. van Beekvelt, K. Orbon, B. G. M. Van Engelen, R. A. Wevers, and W. N. J. M. Colier, "NIR spectroscopic measurement of local muscle metabolism during rhythmic, sustained and intermittent handgrip exercise," in Photon Migration and Diffuse-Light Imaging, vol. 5138 of Proceedings of SPIE, Munich, Germany, June 2003.

[31] X. Game, E. Chartier-Kastler, and A. Ruffion, "Lower urinary tract dysfunction and non-neurogenic neurogenic bladder or "dysfunctional voiding"', Progres en Urologie, vol. 17, no. 3, pp. 406-414, 2007. 


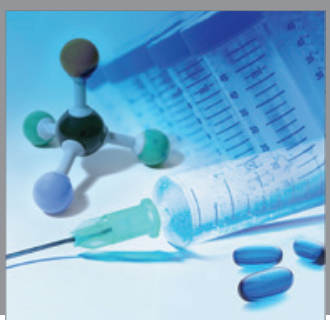

International Journal of

Medicinal Chemistry

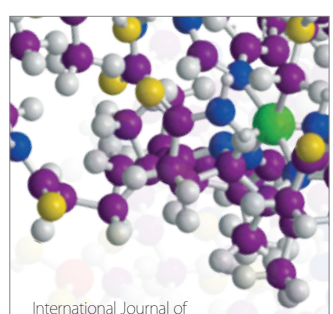

Carbohydrate Chemistry

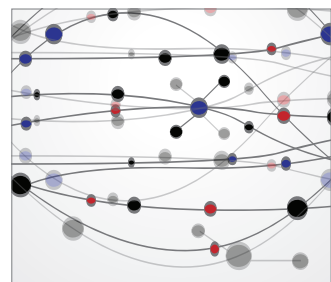

The Scientific World Journal
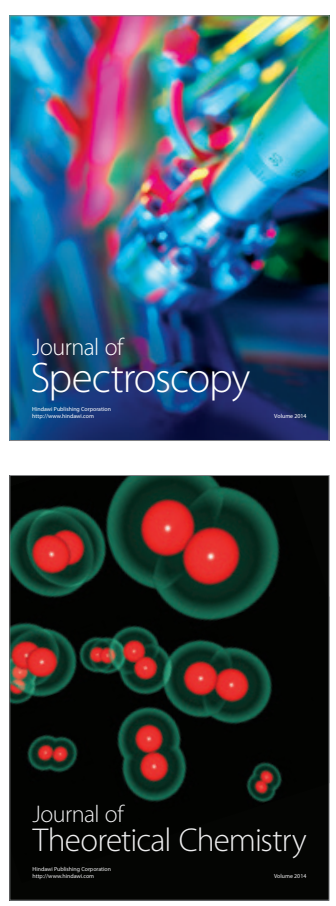
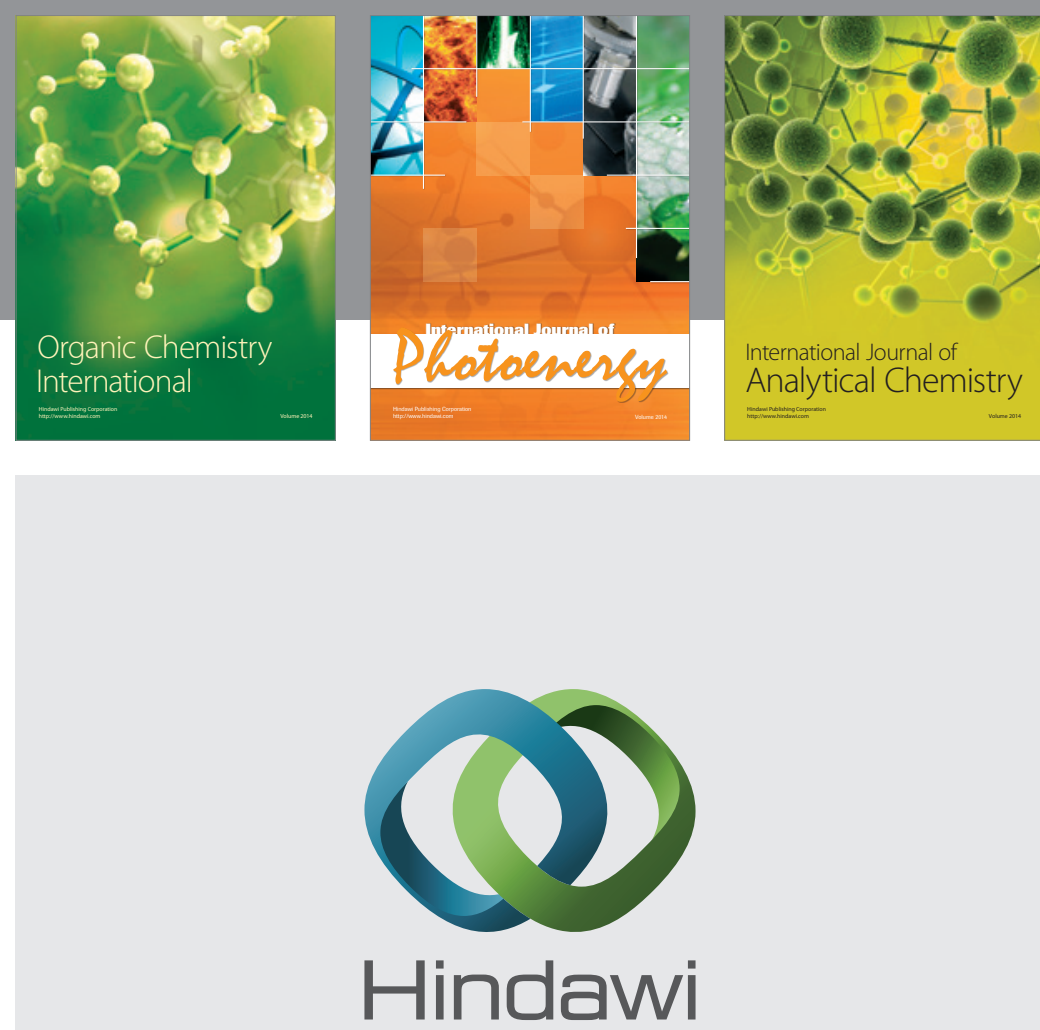

Submit your manuscripts at

http://www.hindawi.com
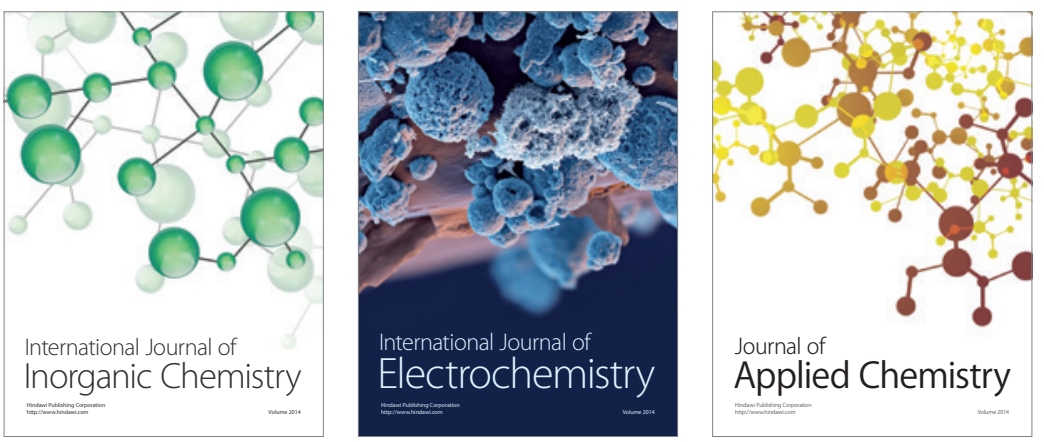

Journal of

Applied Chemistry
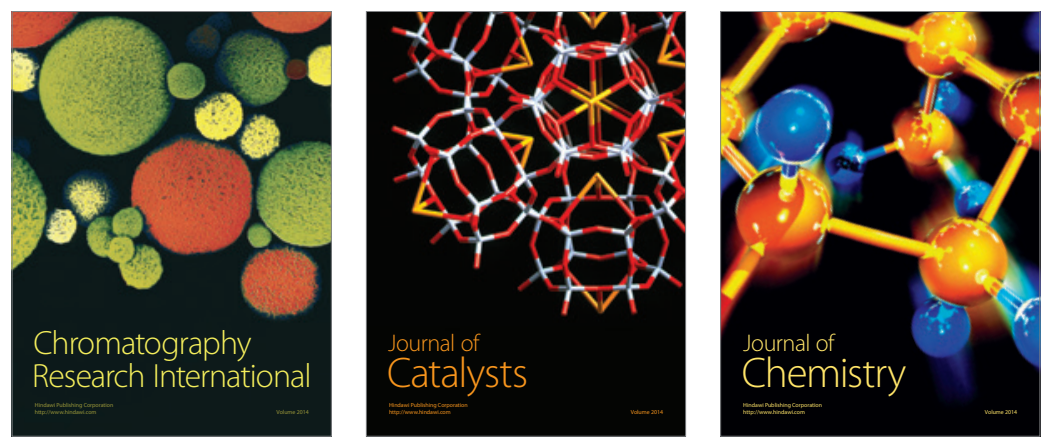
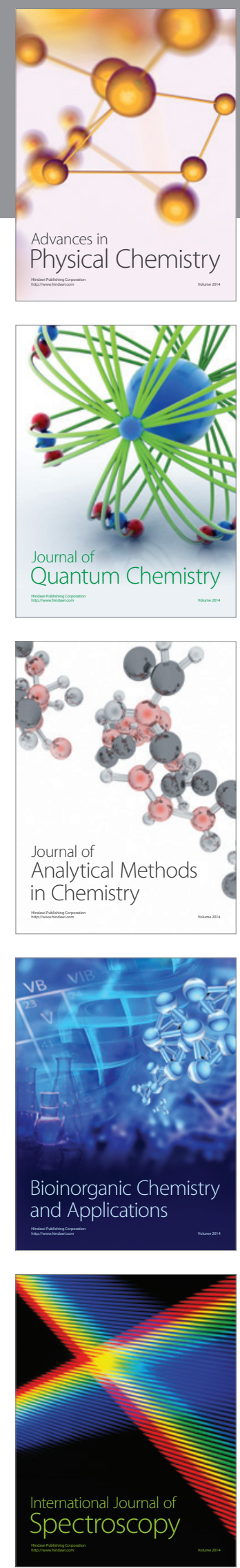